\title{
DIREITO HUMANO AO BOM USO DA CIÊNCIA NA PESQUISA FARMACOLÓGICA: CRITICAS AO MÉTODO CIENTÍFICO E DO PODER SOBRE O CORPO
}

\section{HUMAN RIGHT OF THE GOOD USE OF SCIENCE AND DRUGRE SEARCH: CRISTICISM TO THE SCIENTIFIC METHOD AND POWER OVER THE BODY}

\author{
${ }^{1}$ Diego Fonseca Mascarenhas \\ ${ }^{2}$ Debora Simoes Pereira
}

\section{RESUMO}

A presente proposta de trabalho tem por objetivo avaliar a possibilidade de desenvolvimento do direito humano a uma boa ciência ou um bom desenvolvimento da ciência, por meio do direito alinhavado à bioética, analisando a conjuntura mercadológica dos fármacos, debatendo a violência sobre os direitos fundamentais que a indústria farmacêutica tende a provocar, discutindo o enquadramento do direito e da democracia como elementos de proteção aos direitos fundamentais e observando por intermédio do exercício do poder sobre o controle do corpo dos comportamentos, bem como a necessidade de reintroduzir a discussão ética sobre a verdade da ciência e seu desenvolvimento.

Palavras-chave: Bioética, Poder sobre o corpo, Indústria farmacêutica, Direitos fundamentais

\begin{abstract}
This paper has the objective of evaluate the possibility of development of human right to good science or good science development through the bioethics, analyzing the conjecture marketable pharmaceuticals, debating the violence on fundamental rights that the pharmaceutical industry tends to cause, discussing the framework of law and democracy as an element of protection of fundamental rights and observing thought of exercise of power over the body control behaviors, as well as the need to reintroduce an ethical debate over the truth of science and its development.
\end{abstract}

Keywords: Bioethics, Power over the body, Pharmaceutical factory, Fundamental right

\footnotetext{
${ }^{1}$ Mestre em Direito pela Universidade Federal do Pará - UFPA. Professor da Faculdade de Castanhal - FCAT, Castanhal - PA (Brasil). E-mail: diegomask_85@hotmail.com

${ }^{2}$ Mestre em Direito pela Universidade Federal do Pará - UFPA. Professora da Faculdade de Castanhal - FCAT,

Castanhal - PA (Brasil). E-mail: deboraspereira@yahoo.com.br
} 


\section{INTRODUÇÃO}

O objetivo deste artigo é de assinalar a percepção de que há invasividade do aspecto técnico-científico sobre o aspecto da vida biológica, dentro deste contexto, avaliar a possibilidade de desenvolvimento do direito humano a uma boa ciência e não um bom desenvolvimento da ciência. Tendo isto em vista, busca-se a concretização dos direitos fundamentais em compasso com a bioética na sociedade pós-moderna, com a ênfase crítica no sistema econômico.

Para atingir esta análise crítica de ampla complexidade, será apresentado o raciocínio de Michel Foucault, Habermas, e Gadamer.

A importância do pensamento de Michel Foucault consiste no fato de que o autor é agudo em apontar o diagnóstico de onde estão às devidas intervenções e de problematizar o tema clássico sobre o direito à vida, mas não apenas em relação aos problemas típicos do Estado totalitário vivenciado até meados do século XIX, mas no aspecto do avanço da biotecnologia, onde estão os processos que reduzem o ser humano na sua vida biológica e que interferem e o disciplinam dentro do processo simbólico do próprio mundo da vida como se a cultura do que é o humano fosse se reduzindo, tornando possível uma espécie de "colonização do mundo" da vida pelo fato de reduzir a sua existência ao aspecto da vida biológica.

Então, o que é capaz de ser oferecido nessa perspectiva de vida biológica, é aquilo que você vai aderir de modo sutil, dotando a ciência de um poder sobre as pessoas que antes ela não teria,

Quanto ao desenvolvimento da indústria dos fármacos, é abordada a possibilidade da produção em massa, da distribuição em massa de medicamentos que ainda sejam aprovados por protocolos cientificamente determinados, e mesmo assim há implicações que não são meramente científicas. Dentro deste contexto, é discutido o direito ao bom uso da ciência.

No que diz respeito à referência Habermasiana, consiste em identificar a existência na modernidade de que há duas formas distintas de racionalidade, para que seja viável propor uma solução que fuja da razão instrumental, mas que ainda continue sendo racional, visto que também há em outros autores a percepção da colonização do mundo da vida. Porém, eles falham ao identificar somente a existência da racionalidade instrumental no curso da história da humanidade, apontando para o elemento da irracionalidade, revolução, para fugir desta racionalidade dominadora, como é caso proposto no pensamento social de Karl Marx em que na sua dialética histórica é baseada de que há relação de dominação ou de exploração entre as pessoas ou classes sociais. 
De fato esta percepção da colonização do mundo da vida pelos sistemas começa a interferir na esfera intima do privado, sendo diferenciada quando se trata dos dois autores já citados neste artigo. Para Habermas, há a identificação de que houve uma colonização e, para Foucault, existiu um apequenamento na existência humana o qual causa também uma colonização dentro do próprio processo simbólico do próprio mundo da vida, do elemento cultural do que venha ser tido como saúde.

Por fim, será estabelecido um diálogo com Gadamer para proporcionar a ideia de como a construção do mundo é intersubjetiva ou pelo diálogo; e, a tradição que é o peso daqueles símbolos com os quais já temos que lhe dar como ponto de partida. Ela fixa os limites daquilo que pode ser pensado e do mundo que existe.

Percebe que a realidade e o mundo, são construídos intersubjetivamente por meio da linguagem que projeta imagens que buscam a configuração de mundo. Afinal, como ela é histórica e linguisticamente construída, ela pode também ser histórica e linguisticamente iluminados tesouros esquecidos do passado para desvelar reflexões em torno da saúde humana que foram se tornando opacas ao longo do tempo.

A ciência moderna trata o termo qualidade de vida associado a uma maior longevidade, que se resume ao maior número de anos vividos, então quantifica também a qualidade, ou até a normalidade das atividades sexuais pelo fato de fazer parte das mobilidades, da funcionalidade. E para tudo há o consumo de um remédio para solucionar o problema, mas que ocasiona outro problema.

Partindo-se do pressuposto de que o direito à saúde na modernidade está limitado somente ao conceito de ausência de doença. Esta é uma visão limitada do que venha a ser saúde, pois ela tem que ser coligada com o conceito vida e não com o conceito de doença, conforme era percebida na polis grega.

Se a vida for concebida segundo o modelo da polis, segundo a concepção de que o corpo humano funciona na premissa do equilíbrio, a ciência não tem muito a oferecer devido esta ser marcada pela sua forte intervenção sobre o corpo, que proporciona o desequilíbrio da sua harmonização fisiológica, mas se conceber a vida com a ideia de existência biológica, quem promete melhor perspectiva de vida é a ciência.

A partir do Gadamer é possível fazer crítica em aspectos que são limitados em Habermas. Enquanto o pensamento habermasiano mantém uma confiança mais ou menos ingênua nas comunicações cotidianas e nos procedimentos comunicativos institucionais, Gadamer desconfia disto, e proporciona a radicalidade do diálogo no seu sentido mais 
original, uma radicalidade do diálogo que permite criticar, inclusive, aquilo que é chamado de comunicação na modernidade.

Nessa perspectiva, serão utilizadas as três referências teóricas na pesquisa bibliográfica para desenvolver a metodologia do artigo, com a justificativa de que Foucault ajuda muito mais nos diagnósticos, Habermas em visualizar a solução, e o Gadamer em mostrar porque essa solução pode ser seguida exatamente na medida em que existe uma intersubjetividade do problema que requer dialogar e buscar a autenticidade de sentido na vinculação obrigatória com a tradição.

\section{O RISCO DE ESVAZIAR O SIGNIFICADO DA VIDA}

Conforme ficou estabelecido preliminarmente na apresentação deste artigo, a idéia de sistema possui certo ângulo da vida social caracterizada pelo funcionamento autônomo, com a significação de obedecer a uma lógica e uma por uma dinâmica própria através de código próprio. Toda dinâmica é interna e que não está em princípio sofrendo interferências do mundo exterior

Segundo Habermas, sociedades modernas são integradas não somente através de valores, normas e processos de entendimentos, mas também sistemicamente, através de mercados e do poder administrativo. Dinheiro e poder administrativo constituem mecanismos da integração social, formadores de sistema, que coordenam as ações de forma objetiva, como que por trás das costas dos participantes da interação, portanto não necessariamente através da sua consciência intencional ou comunicativa. A mão invisível do mercado constitui, desde a época de Adam Smith, o exemplo clássico para esse tipo de regulamentação. Ambos os meios ancoram-se nas ordens do mundo da vida (HABERMAS, 2003, p. 61).

Portanto, o mercado é reconhecido como uma estrutura impessoal, funcionando a partir de todas as questões estruturais. A sua função é a realização de lucro e são cegas para outros propósitos.

Com efeito, as sociedades modernas se reproduzem ao longo do tempo. O fato ocorre em duas formas: a reprodução simbólica a reprodução material. Esta consiste basicamente em dois elementos, na sobrevivência e no desenvolvimento.

Para que os sistemas tenham bom funcionamento, é preciso operar os dois elementos. Ademais, não é ideal para as sociedades modernas ser livre do mercado devido a sua complexidade. No entanto, se deve limitar a ação deles, pelo fato de considerar que esses são 
indispensáveis nas sociedades modernas, em virtude de serem responsáveis pela reprodução material.

Ainda, a ação exercitada é a ação instrumental, no sentido de reunir meios para alcançar fins, conectar meios à fins por meio da seleção dos meios disponíveis com vistas ao alcance maior e que seja mais rápido para o sistema econômico alcançar o seu propósito.

Nessa linha de investigação, Foucault visualiza no século XIX o nascimento da biopolítica com a tese de que o neoliberalismo é, na verdade, uma forma de Estado Totalitário. Ao contrário do que este anunciou, de que seria um Estado liberal, percebe-se que este intervém nos domínios econômicos principais. Da mesma forma, é ao mesmo tempo um sistema em que todas as relações humanas são reduzidas ao econômico, ao estatístico.

Designei grosseiramente como conexão à razão de Estado, e cálculo da razão de Estado, de certo regime de verdade, o qual encontrava sua expressão e sua formulação teórica na economia política. O aparecimento da economia política e o problema do governo mínimo eram duas coisas interligadas. (FOUCAULT, 2008, p. 41)

É importante destacar que se tudo for reduzido ao econômico e o Estado Neoliberal pode intervir no econômico, ele poderá ser capaz de intervir em tudo, basta que seja reduzido ao econômico por meio da elaboração da estatística o resultado e a sua projeção econômica.

Para poder lutar contra um Estado (...), uma das primeiras coisas a compreender é que o poder não está localizado no aparelho de Estado e que nada mudará na sociedade se os mecanismos de poder que funcionam fora, abaixo, ao lado dos aparelhos de Estado a um nível muito mais elementar, quotidiano, não forem modificados (FOUCAULT, 1990, p. 149-150)

A tese suscitada por Foucault se endereça na direção da idéia de colonização do mundo da vida com aplicação na questão dos fármacos. A perturbação da saúde consiste no gasto de bilhões em pesquisas no desenvolvimento de medicamentos com maior projeção econômica como nos remédios para terapia da melhoria do desempenho sexual, como o tão famoso Viagra e seus derivativos, e também o desenvolvimento da flibanserina que é o princípio ativo sexual feminino como é o Viagra para o masculino, previsto o seu lançamento no mercado no ano de 2015.

Será que a sociedade não tem outras doenças, outras necessidades muito mais antigas, porém não há mercado e, consequentemente, não há nenhuma pesquisa sendo desenvolvida por parte das grandes indústrias farmacêuticas. Quando há pesquisas, elas são desenvolvidas por universidades para quais são necessárias as quebras de patente.

O controle da sociedade sobre os indivíduos não se opera simplesmente pela consciência ou pela ideologia, mas começa no corpo, com o corpo. Foi no biológico, no somático, no 
corporal que, antes de tudo, investiu a sociedade capitalista. O corpo é uma realidade biopolítica. A medicina é uma estratégia biopolítica. Ora, não é o consenso que faz surgir o corpo social, mas a materialidade do poder se exercendo sobre o próprio corpo dos indivíduos (FOUCAULT, 1990, p. 80-146).

Acentuamos que não só sistema econômico, mas também o sistema político é organizado autopoieticamente, por ser organizado sistemicamente. Não são influenciados por outros aspectos, eles têm uma dinâmica própria e funcionam só a partir dessa dinâmica.

Os sistemas da economia e da administração têm a tendência de fechar-se contra seus mundos circundantes e de obedecer unicamente aos próprios imperativos do dinheiro e do poder administrativo. Eles rompem o modelo de uma comunidade de direito que se determina a si própria, passando pela prática dos cidadãos. (HABERMAS, 2003, p. 109).

Jürgen Habermas aponta como objetivo primordial a preocupação do futuro da natureza humana relacionado com o desenvolvimento da ciência, que podem ser devidamente amoldados ao campo dos sistemas ao Direito Humano. A autonomia da pesquisa adquire proteção a partir da perspectiva do Estado constitucional liberal. Com efeito, com o alcance e a profundidade crescentes da disposição da técnica sobre a natureza, tanto a promessa econômica de progressos na produtividade e de aumento do bem-estar quanto esperança política de maiores margens de decisão individuais encontram-se unidas (HABERMAS, 2004, p. 37$34)$.

Contudo, no ponto da reprodução simbólica das sociedades modernas, há o mundo da vida. Nela contêm a arte, a religião, ciência, moral e o direito. Segundo Habermas, muito além de influenciadores, eles influenciam uns aos outros. Não são dinâmicas fechadas, se relacionam diretamente uns com os outros, porque todos são integrados via comunicação.

A propósito, no âmbito comunicativo inserido no mundo da vida, o intento é chegar ao entendimento através do uso da linguagem. Visto que, o mundo da vida exige que as teorias científicas da medicina se formem apoiadas em prova, em virtude da obrigatoriedade delas serem legitimadas por certos métodos. Afinal, é a forma de produzir convencimento a todos.

As pessoas só estarão convencidas das mesmas teses, se elas estiverem apoiadas em provas, só terá confiança nelas se forem orientadas por métodos confiáveis e éticos, então, se trata da ciência de chegar a um entendimento, de chegar num consenso, em termos habermasianos, para chegar sobre o que é verdade, sobre o que é verdadeiro em cada caso. Então, a ciência tem que se portar de maneira comunicativa, tem que se utilizar o uso da linguagem e tem que ter como propósito final o de alcançar o entendimento entre sujeitos. 
A idealidade da validade em termos de verdade só se expressa nos pressupostos pretensiosos de nossa prática de justificação, portanto no nível do uso da linguagem. Nisso se revela o nexo interno que existe entre a validade de uma proposição e a prova de sua validade para um auditório idealmente ampliado. O que é válido precisa estar em condições de comprovar-se contra as objeções apresentadas factualmente. Como no caso do caráter ideal do significado em geral, na linguagem, a dimensão da validade constitui-se através de uma tensão entre facticidade e validade: a verdade e as condições discursivas para a aceitabilidade racional de pretensões de verdade esclarecem-se mutuamente (HABERMAS, 2004, p. 56).

A esfera comunicativa é caracterizada por um propósito de alcançar um entendimento e para alcançá-lo é utilizado o meio de circulação a própria linguagem; enquanto no sistema econômico e no sistema político o meio de comunicação é o dinheiro e o poder, respectivamente.

Em contraposição a função dos sistemas está o mundo da vida, em face de ser responsável pela reprodução simbólica. Contudo, uma sociedade para se manter ao longo do tempo deve se reproduzir materialmente com o intuito de manter bens materiais para a sua sobrevivência e o seu desenvolvimento, mas também precisa estar se reproduzindo simbolicamente.

É preciso que às pessoas estejam chegando a acordos comuns para obter aquisição de valores. O mundo da vida é a esfera indispensável da vida social para que exista a reprodução simbólica e na sua ausência compromete a integração social e a solidariedade.

Por outro, acontece não só a relação do sistema econômico, como também o sistema político sobre o mundo da vida na tentativa de colonizá-la. A economia via mercantilização e a política mediante da própria burocratização. Eles invadem aspectos que são originalmente comunicativos, regulando-o com o funcionamento racional instrumental, ameaçando atores de integração e solidariedade.

Como integrar socialmente mundos da vida em si mesmos pluralizados e profanizados, uma vez que cresce simultaneamente o risco de dissenso nos domínios de agir comunicativo desligado de autoridades sagradas e de instituições fortes? Após a descrição dessa cena, parece que a necessidade crescente de integração, nas modernas sociedades econômicas, sobrecarrega a capacidade de integração do mecanismo de entendimento disponível, quando uma quantidade crescente de interações estratégicas, imprescindíveis para a estrutura social, são liberadas. Num caso de conflito, os que agem comunicativamente encontram-se perante a alternativa de suspenderem a comunicação ou de agirem comunicativamente - de protelarem ou de tentarem decidir um conflito não solucionado (HABERMAS, 2004, p.46). 
A colonização é o mais alto risco que as sociedades modernas têm. A cada dia, a esfera de influência do mercado é maior, tanto que quem não obedecer à lógica do mercado, o lucro, é eliminado. O sistema econômico tem dinâmica estrutural não comunicativa, o mercado é impessoal, funciona à revelia da vontade de qualquer sujeito, cabendo aqui expor a idéia de Habermas, a fim de expor a tendência dos Direitos Humanos a se comportar perante este cenário.

Para além dos limites de uma comunidade de pessoas morais, compreendida em seu sentido estrito, não se estende nenhuma zona cinzenta em que poderíamos agir sem levar em conta as normas e manipular sem entraves o que quisermos. Por outro lado, conceitos jurídicos moralmente saturados, como "direito humano" e "dignidade humana", perdem, devido a uma excessiva extensão contra-intuitiva, não apenas sua acuidade, mas também seu potencial crítico. Lesões ao direito humano não podem ser reduzidas a infrações às representações axiológicas. Aquilo que se tornou tecnicamente disponível por meio da ciência deve voltar a ser normativamente indisponível por meio do controle moral (HABERMAS, 2004, p. 52-34).

Como foi dito antes, é perceptível a preocupação do caso dos fármacos sobre a experimentação desenvolvida nos sifilíticos ou na invasão da esfera privada do indivíduo que artificializa as relações mais íntimas entre os sujeitos com o estimulo do consumo de estimulante sexual, como é o caso do Viagra.

O progresso na ciência e na tecnologia biomédica e sua aplicação na prática da medicina provocam inquietações na população e fazem com que a sociedade se confronte com novos problemas éticos. A sociedade expressa sua preocupação sobre o que poderiam ser abusos na investigação científica e na tecnologia biomédica. Isso é compreensível, em vista da metodologia da pesquisa biomédica experimental (PESSINI, 2005, p. 213).

De fato, Hans-Georg Gadamer aborda que há oposição sempre entre verdade e método, pelo fato da verdade só poder ser compreendida simbolicamente e o método ser uma recusa ao simbólico.

O método é uma espécie de formalização de um procedimento a partir do qual é considerado como verdadeiro aquilo que está facultado nos requisitos formais. Nesse contexto, ocorre a renúncia do pensar e o indivíduo passa a ser aplicador do método, ou seja, onde há verdade não há método, onde há método, não há verdade. Esses conceitos se opõem um ao outro. 
Como eles se opõem, só pode haver verdade numa perspectiva compreensiva hermenêutica, mas exatamente por isso que a hermenêutica não pode ter método pelo motivo daquela ser uma autocompreensão, cujo modelo básico é o diálogo.

O modelo básico da hermenêutica é o entendimento entre um sujeito e outro, enquanto a ciência faz o contrário disso. Ela faz a proclamação da ideia de que o nosso entendimento mútuo só gera o senso comum que não tem valor teórico nenhum, o que tem valor teórico é aquilo que posso comprovar ou descobrir por via de um método.

O método é validação desse procedimento. No sentido de que o entendimento e a comunicação não têm valor cognitivo na perspectivada da ciência, tendo no máximo um valor prático aparente, sendo que a única coisa que tem valor cognitivo é a própria ciência.

A compreensão que o Gadamer está criticando, é exatamente o ponto de vista que vai levar a colonização por meio da intervenção científica no domínio do privado e no domínio da vida do caso dos fármacos.

Por outro lado, conhecemos a perspectiva exterior do mundo e, entre todas as suas formas de aparição, também nossas experiências corporais, cujo objeto a ciência moderna, com seu procedimento metodológico, trouxe para a objetivação, uma investigação da qual a ciência não pode se esquivar e cujos resultados a pratica não pode ignorar. Mas isso não exclui a possibilidade de percebermos os limites daquilo que, dessa maneira, é reconhecível e a possibilidade de que isso desperte uma consciência hermenêutica para se admitir os limites da objetividade geral. Assim, coloca-se a questão: como ambas podem andar juntas, a experiência do corpo e a ciência? (GADAMER, 2006, p. 78-79).

\section{A VINCULAÇÃO ENTRE DIREITO E SAÚDE}

Gadamer assinala que quem constrói o mundo somos nós, sujeitos, e nós construímos a partir do entendimento de que é intersubjetivo, numa relação sujeito/sujeito, e de uma interpretação que nós fizemos das situações em que vivemos.

Isso significa que a influência que a ciência tem, também é uma influência que vai se construindo intersubjetivamente. É uma "autoridade" que ela não tem por si, porque ela não pode conhecer o mundo em si, pois o mundo em si não existe. Isto está fora do campo cognitivo do homem. Isso é possível intersubjetivamente. Assim, se a autoridade da ciência foi construída intersubjetivamente, ela também pode ser desconstruída intersubjetivamente para que haja a revelação do ser. 
Pode-se colocar isso sob uma lupa e julgar o seu grau de doença através de todos os modos que uma ciência objetivante, em virtude da ciência natural moderna, nos colocou à disposição. No entanto, saúde é algo que se subtrai a tudo isso de uma maneira peculiar. Saúde não é algo que se apresenta como tal num exame, mas algo que existe justamente por se subtrair a um exame. Corpo e vida afiguram-se-me sempre como umalespécie de dados da experiência que giram em torno da perda de equilíbrio à procura de novas situações de equilíbrio. Esse modelo parece-me exatamente o modelo de origem do nosso modo de ser humano corporal, e não somente corporal (GADAMER, 2006, p.103-86).

Contudo, o mundo da vida tem a capacidade de mesmo quando ele é colonizado, acabar se habituando à colonização. O papel para impedir a colonização é feito pela democracia e pelo o direito.

De um lado, é necessário que o direito continue insistindo que os sistemas dirigidos pelo o dinheiro e pelo poder administrativo não fujam inteiramente a uma integração social mediada por uma consciência que leva em conta a sociedade como um todo; de outro lado, parece que essa pretensão é vítima do desencantamento sociológico do direito (HABERMAS, 2003, p. 65).

Pois bem, no aspecto da positividade, o direito vigente considerado isoladamente, permite a abstração do consenso devido o efeito da própria positivação da norma torná-la como obrigatória, impondo, inclusive, para quem discorde dela.

$\mathrm{O}$ direito tem igual capacidade de comunicação com o mundo da vida, podendo colonizá-lo via sistemas ou emancipá-lo. A comunicação se dá por meio duas características, a coercitividade e a legitimidade.

Em primeiro lugar, A coercitividade tem haver com controle de impor algo obrigatório, punindo para que seja cumprido, como também desempenha o papel de preencher e de estabelecer parâmetros éticos necessários para o mundo da vida. Fato notado devido à sociedade pós-moderna ter passado pela dessacralização da visão de mundo, ela não se baseia mais na religião como ocorria durante a idade média. Perdeu a sua capacidade de motivação, pelo fato da religião e o modo como ela via o mundo criava um potencial para o seu modelo ético. Atualmente, não há um correspondente na modernidade do momento que a religião foi deslocada para o centro do pensamento positivo.

É um mundo da vida que exige razões, fundamentos. Argumentos para fazer as coisas e mantê-lo funcionando ao longo do tempo. Então, a característica da coercitividade se conecta racionalmente com o mundo da vida. 
Aliás, a emancipação ocorre quando o mundo da vida consegue preservar a sua autonomia contra as interferências invasivas dos sistemas.

Dado que a positividade do direito resulta da racionalização de suas bases de validade, o direito moderno conseguirá estabilizar as expectativas de comportamento de uma sociedade complexa, que inclui mundos da vida estruturalmente diferenciados e subsistemas funcionalmente independentes, se ele assumir a função de lugar-tenente de uma "societal community" que se transformou numa sociedade civil, mantendo a pretensão de solidariedade herdada, na forma de uma pretensão de legitimidade digna de fé. Modernos sistemas de direito procuram cumprir essa promessa, através da generalização e da concretização do status de cidadania (HABERMAS, 2004, p. 105).

Em segundo lugar, a legitimidade no direito consiste que o próprio tenha eficácia ao longo do tempo. Se ele não conseguir se apresentar como um direito racionalmente aceitável para os destinatários, não conseguirá um alto e duradouro índice de obediência ao longo do tempo. A questão que vai ligar o direito à democracia é exatamente como o direito vai poder alcançar essa legitimidade.

Assim, assinala Habermas que o princípio da soberania popular, segundo o qual todo o poder do Estado vem do povo, o direito subjetivo à participação, com igualdade de chances, na formação democrática da vontade, vem ao encontro da possibilidade jurídico-objetiva de uma prática institucionalizada de autodeterminação dos cidadãos. Esse princípio forma a charneira entre o sistema dos direitos e a construção de um Estado de direito (HABERMAS, 2003 p.212).

Problematizando novamente, devido ao pluralismo das sociedades modernas, os indivíduos passam a ser, cada vez mais, deferentes uns dos outros. Passando cada vez a ter projetos de vida mais peculiares, mais distintos, preferências distintas, valores distintos, bibliografias que se distinguem muito uma das outras.

Durante o percurso da história da humanidade surgiram quatro escolas da filosofia moral que floresceram e influenciaram no seu ambiente próprio de origem, dentre elas são: o aristotélico ou realismo moral, firmado na justificação ontológica de normas e valores por meios metafísicos (HABERMAS, 2004, p.22) e com o comunitário; o utilitarismo, baseado no cálculo de custo e benefícios na busca do bem comum; o ceticismo moral, o qual afirma que não é possível decidir questões morais pelo motivo de se tratar de questões irracionais e subjetivas; o kantiano ou funcionalismo moral relacionado com o caráter deontológico, visando o tipo de pessoa que devo ser, como também com o universalismo moral em virtude de impor deveres morais para todos independentemente de cada projeto de vida em particular. 
As quatro escolas citadas influenciam simultaneamente a sociedade pós-moderna, ao considerar que não há mais o perfeito contexto de justificação em que elas foram constituídas. $\mathrm{Na}$ verdade, no contexto atual, há apenas fragmentos dessas morais em frangalhos, com as suas respectivas aplicações inconciliáveis entre si.

O desafio é adotar não um modo coerente de pensar e julgar, mas uma visão construída a partir de uma amálgama de fragmentos sociais e culturais herdados tanto de diferentes tradições das quais nossa cultura originalmente proveio (puritana, católica, judaica), como de diferentes estágios e aspectos do desenvolvimento da modernidade. Portanto, freqüentemente, nos desacordos que emergem dentro de nós mesmos, assim como aqueles que são objeto de conflito entre nós e os outros, somos forçados a enfrentar a seguinte questão: como devemos escolher entre visões opostas e incompatíveis de justiça que porfiam por nossa adesão moral, social e política (MACINTYRE, 2001, p. 12)? Em outras palavras, a linguagem e as aparências da moralidade persistam; embora a substância integral da moralidade tenha se fragmentado muito e, assim, tenha sido, em parte, destruída (MACINTYRE, 2001, p.20).

A filosofia hoje não consiste, como já foi um dia, num conjunto de conselhos práticos acerca do que seria uma vida boa e feliz. A filosofia fica restrita às questões de justiça e moral e passa a analisar apenas as propriedades formais dos processos de tomada de decisão moral e jurídica sem opinar sobre os conteúdos das formas de vida ética. Em grande parte, a adoção da perspectiva procedimentalista não é uma opção, mas sim, quase uma imposição, após a derrocada das respostas metafísicas às questões éticas, morais e de justiça (FELDNAUS, 2005, p.309).

A percepção é clara que cada vez se torna mais difícil o direito se legitimar pelo conteúdo, o obstáculo que vai fazer com que o direito não possa ser legitimado pelo seu conteúdo, considerando que não existe nenhum conteúdo que seria aprovado pelos valores dos outros, não existe nenhum conteúdo capaz de obter sozinho o assentimento de todos devido às visões de mundo e os valores serem os mais diversos.

Nesse sentido, é necessário que o direito passe a se estruturar com a forma de legitimação, não pelo seu conteúdo, pelo contrário, pela a sua estrutura de formação, com o modo de formação. Porventura, nesse momento da modernidade, a solução política encontrada na solução deste problema foi à democracia.

O conceito de uma política deliberativa que promova o diálogo só ganha referência empírica quando faz jus à diversidade das formas comunicativas na qual se constitui uma vontade comum, não apenas por um autoentendimento mútuo de caráter ético, mas também pela 
busca de equilíbrio entre interesses divergentes e do estabelecimento de acordos, da checagem da coerência jurídica, de uma escolha de instrumentos racional e voltada a um fim específico e por meio, enfim, de uma fundamentação moral (HABERMAS, 2004, p. 285).

A idéia de autonomia corporificada no sistema democrático se transforma na nova maneira de legitimação do direito vigente. $\mathrm{O}$ direito está legitimado não porque ele tem um conteúdo com o qual todos concordam, indistintamente, mas porque ele foi formado por meio de um processo que permitiu a participação de todos e nesse sentindo é produzido à deliberação daqueles membros que são submetidos a ele, como um produto de uma autoimposição jurídica.

$\mathrm{O}$ direito e a moral são distintos, sob vários aspectos, mas não separados: “A legitimidade do direito não deve ser assimilada à validade moral, nem deve o direito ser separado completamente da moral", pois os conteúdos morais que adentraram no direito devem ter prioridade sobre as demais razões que também adentraram nele. Vale lembrar, o direito não pode contradizer normas morais (DULTRA, 2006, p. 37).

O desafio, então, é determinar como o direito poderá impor tarefas éticas; nas palavras do autor, o processo de apresentação vai do abstrato ao concreto, sendo que a concretização acontece porque a perspectiva da representação, inicialmente trazida de fora, é internalizada pelo sistema de direitos, representados. Isso depende explicitamente dos meios capazes de introduzir em abstrato a norma geradora de direitos, devidamente descritos por Habermas:

a) Direitos fundamentais que resultam da configuração politicamente autônoma do direito à maior medida possível de iguais liberdades subjetivas de ação;

b) Direitos fundamentais que resultam da configuração politicamente autônoma do status de um membro numa associação voluntária de parceiros do direito;

c) Direitos fundamentais à participação, em igualdade de chances, em processos de formação da opinião e da vontade, nos quais os civis exercitam sua autonomia política e através dos quais eles criam direito legítimo;

d) Direitos fundamentais a condição de vida garantidas social, técnica e ecologicamente, na medida em que isso for necessário para o aproveitamento, em igualdade de chances, dos direitos elencados.

O mais novo ramo da filosofia moral poderá definir, assim, não um código de normas substantivas, que sirva de guia para as políticas de saúde e de pesquisa biológica, mas sim analisar as condições racionais para a existência de argumentos, fundadores de princípios, que serão materializados através da ordem jurídica, e visem resguardar a pessoa humana e os seus descendentes. Os problemas bioéticos referem-se em sua amplitude às condições de 
conservação e melhoria da própria condição humana, que se expressam no estado da saúde de cada pessoa, reflexo não somente de condições físicas ou psíquicas do indivíduo, mas, também, de políticas públicas e da prática da medicina. Nesse sentido, a bioética insere-se na tradição da ética prática, analisando o ponto de vista ético a prática da medicina e, também, os fundamentos e objetivos das políticas públicas de saúde (TORRES, 2001, p. 400).

Desse modo, a partir da compreensão do autor referido em relação aos objetivos da proposta ora apresentada, há de se constatar que a análise do direito humano a um desenvolvimento da ciência com críticas à lógica de mercado é amplamente viável, se amoldada a partir de estudos concretos e específicos, que levem em consideração a violação dos direitos fundamentais operante na sociedade moderna.

\section{CONSIDERAÇÕES FINAIS}

Como se sabe, o direito, especificamente os direitos humanos, é um importante fator de estabilidade social, pois é capaz de impor limites éticos ao comportamento humano, alhures nominadas de risco ${ }^{1}$.

Não obstante tal constatação, observa-se que a busca pelo o entendimento de delimitação e imposição de fronteiras éticas ainda é difícil, principalmente se levarmos em conta a pluralidade de visões éticas existente na pós-modernidade, pleitear proteção jurídica requer o preenchimento de eticidade nos direitos humanos, o que denota novamente a dificuldade de universalização de valores na sociedade moderna.

A descoberta dos fatores torna-se preocupante com a inserção da lógica de mercado farmacológica como sendo efeito degenerado a saúde pública. Com efeito, tal ponto poderá ser analisado pelo viés da fácil aceitação da sociedade moderna em ceder aos interesses farmacológicos, percebida por meio da análise da Teoria Crítica da Escola de Frankfurt, tanto em termos socias quanto em termos estruturais econômicos.

Outro ponto nefrálgico implica a avaliação entre verdade e método na ciência moderna. Ela está voltada para garantir o rigor metodológico e desconsidera o elemento simbólico ou implicações éticas em que as suas pesquisas desenvolvidas podem impactar na sociedade.

\footnotetext{
${ }^{1}$ Segundo Bobbio, pode-se imaginar a história como um imenso mar de gente fechado com diques: os diques são regras de condutas, religiosas, morais, jurídicas, sociais, que mantiveram a corrente das paixões, dos interesses e dos instintos dentro de certos limites e permitiram a formação daquelas sociedades estáveis, com suas instituições e seus ordenamentos, que chamamos de "civilização" (2008, p. 4).
} 
No contexto de tempo e espaço o tema sobre Direito e saúde ganha importância peculiar. Em 11 de novembro de 1997, houve a Declaração da UNESCO, proporcionando uma proposta de formalização cosmopolita da bioética aos Direitos Humanos. Cabe, portanto, avaliar a bioética transformando-a na mais recente fonte dos Direitos Humanos no sentido da bioética caminhar para o biodireito, objetivando permitir a recuperação do sentido ético original.

Quando se está diante desse fato, coloca-se, então, a questão fundamental: se em nossa situação mundial não haverá tarefas da existência humana, cujo agravamento através do ethos de rendimento da ciência humana coaja nossa cultura ocidental a um auto-exame crítico. Nós devemos estar conscientes disso e eu já me referi expressamente sobre o significado de irmos ao encontro de uma civilização mundial na qual perfectibilidades técnicas se misturam com novas e diferentes correntes tradicionais de vida cultural e talvez nos conduzam a novos impulsos para a realização de nossas tarefas para com a humanidade (GADAMER, 2006, p. 78-79).

No aspecto de que visa circunscrever o direito à racionalidade cristalizada nos produtos da atividade legislativa. O direito não é só autocritativo no sentido da coação, do tempo, da jurisprudência, mas do caráter dogmático dos argumentos que o legislador preceituou [Geltung]. Parte do fato de que os ordenamentos jurídicos incorporaram, senão todos os direitos humanos, ao menos boa parte deles. Assim, grande parte da argumentação moral já está no sistema jurídico. A questão que remanesce é como determinar os efeitos desses argumentos dentro do ordenamento, no que concerne à sua configuração no de interpretá-lo ao extrair do texto o seu sentido. Hoje em dia, parece ser difícil encontrar uma norma que seja injusta do ponto de vista moral, e que não possa ser resolvida pelos argumentos normativos já preceituados no ordenamento jurídico.

Outrossim, o espaço no qual a pesquisa será desenvolvida é bastante apto ao seu êxito, tendo em conta que o sistema econômico tende tratar a sociedade como meio para atender as suas próprias finalidades, seus objetivos financeiros. Tratando os sujeitos como objetos. Nesse contexto, há a necessidade dentro da discussão bioética de haver o tratamento do tipo sujeitosujeito para que seja alcançada a solidariedade e a integração social, com a finalidade de buscar o entendimento via comunicação.

O entendimento deve ser instituído no debate racional dentro da sua condição no mundo por via da dialógica ou comunicacional, para que seja esculpida a ordem jurídica. Caso contrário, os valores e princípios bioéticos irão ser expressos pelo Estado ou cientistas que possuem em sua posse o saber especializado. 
Parte-se da análise dos Direitos Humanos à Bioética como fator de saúde pública, buscando garantir os princípios da bioética. Estes deixam, então, de representar determinações canônicas e passam a constituir uma forma de direito cosmopolita. O projeto volta-se ao estudo da vulnerabilidade da sociedade moderna, tendo como ponto crítico ao desenvolvimento de conjuntura do sistema normativo no viés procedimental no âmbito nacional e internacional.

\section{BIBLIOGRAFIA}

BOBBIO, Noberto. Teoria geral do direito. 2. ed. Trad. Denise Agostinetti. Revisão trad. Silvana Cobucci Leite. São Paulo: Martins Fontes, 2008.

Dultra, Delamar José Volpato. A teoria da aplicação do direito: o modelo de Habermas. Revista Veritas, v. $51 \quad \mathrm{n}^{\mathrm{o}}$. 1, março/2006. Disponível em: http://revistaseletronicas.pucrs.br/ojs/index.php/veritas/issue/view/182. Acesso em 23 mar. 2012

Feldhaus, Charles. O futuro da natureza humana de Jürgen Habermas: um comentário. Revista ethic@,v. 4 nº.3, dez/2005. Disponível em: http://www.cfh.ufsc.br/ethic@/. Acesso em 27 fev. 2012.

FOUCALT, Michel. Nascimento da biopolítica: curso dado no Collège de France: 1978 1979. Trad. Eduardo Brandão; revisão da trad. Claudia Berliner. São Paulo: Martins Fontes, 2008

Graal, 1990.

. Microfísica do Poder. 9 ed. Trad. Roberto Machado. Rio de Janeiro: Rio de Janeiro:

GADAMER, Hans-Georg. Verdade e Método II: complementos e índice. 2 ed. Trad. Enio Paulo Giachini; revisão da trad. Marcia Sá Cavalcante Schuback. Rio de Janeiro: Vozes;São aulo: Editora Universitária São Francisco, 2004.

. O Caráter Oculto da Saúde. Trad. Antonio Luz Costa. Rio de Janeiro: Vozes, 2006.

HABERMAS, Jürgen. Direito e democracia: entre facticidade e validade. Trad. Flávio Beno Siebeneichler. Rio de Janeiro: Tempo Brasileiro, 2003.

. A inclusão do outro: estudos de teoria política. 2. ed. Trad. George Sperber, Paulo Astor Soethe, Milton Camargo Mota. São Paulo: Loyola, 2004.

2004.

. O futuro da natureza humana. Trad. Karina Jannini. São Paulo: Martins Fontes, Revista de Biodireito e Direitos dos Animais | e-ISSN: 2525-9695| Brasília | v. 2 | n. 1 | p. 145 - 161 | Jan/Jun. 2016. 
MACINTYRE, Alasdair. Depois da Virtude: Um estudo em teoria moral. Trad. Jussara Simões. São Paulo: EDUSC, 2001.

. Justiça de quem? Qual racionalidade?. 2 ed. São Paulo: Edições Loyola, 2001.

PESSINI, Leo. Problemas atuais de bioética. São Paulo: Edições Loyola, 2005.

TORRES, Ricardo Lobo (coord.). Teoria dos Direito Fundamentais. 2 ed. Rio de Janeiro: Renovar, 2001. 